\title{
Data mining for municipal financial distress prediction
}

\author{
David Alaminos \\ PhD Student. Department of Finance and Accounting. University of Malaga, Malaga, \\ Spain. \\ alaminos@uma.es \\ Sergio M. Fernández \\ PhD Student. Department of Languages and Computer Sciences. University of \\ Malaga, Malaga, Spain. \\ Zsergiofernandezmiguelez@uma.es \\ Francisca García \\ Associate Professor. Department of Applied Economics. University of Malaga, \\ Malaga, Spain. \\ fg_lopera@uma.es \\ Manuel A. Fernández \\ Associate Professor. Department of Finance and Accounting. University of Malaga, \\ Malaga, Spain. \\ $>$ mangel@uma.es
}

\begin{abstract}
Data mining techniques are capable of extracting valuable knowledge from large and variable databases. This work proposes a data mining method for municipal financial distress prediction. Using a new proxy of municipal financial situation and a sample of 128 Spanish municipalities, the empirical experiment obtained satisfactory results, which testifies to the viability and validity of the data mining method proposed for municipal financial distress prediction.
\end{abstract}

Keywords: Financial distress prediction, Data mining, Municipalities, Individual classifiers, Local governments 